\title{
Contribution of the nasal passage to face mask ventilation: a prospective blinded randomized crossover trial
}

\section{La contribution des voies nasales à la ventilation au masque : une étude croisée randomisée prospective en aveugle}

\author{
Tomoki Yamasaki, MD • Nobuyasu Komasawa, MD, PhD • Haruki Kido, MD, PhD • \\ Toshiaki Minami, MD, PhD
}

Received: 30 October 2016/Revised: 5 May 2017/Accepted: 12 June 2017/Published online: 16 June 2017

(c) Canadian Anesthesiologists' Society 2017

\begin{abstract}
Background Previous studies have shown that the nasal passage plays an important role in manual face mask ventilation, but this has yet to be quantitatively assessed. We conducted a prospective randomized crossover clinical trial to compare the change in pressure-controlled face mask tidal volume with and without nasal airway occlusion.

Method Female patients undergoing elective surgery under general anesthesia served as study subjects. Patients were randomly assigned to face mask ventilation beginning either with or without nasal passage occlusion (achieved with a swimmer's nose clip), followed by removal or application of the nose clip, respectively. After standardized induction of general anesthesia and muscle paralysis, a tight-fitting face mask was applied to each patient, and tidal volume was measured by the anesthesia machine during pressure-controlled ventilation (10, $15,20 \mathrm{~cm} \mathrm{H}_{2} \mathrm{O} ; 8$ breaths.min ${ }^{-1}$; inspiratory: expiratory ratio $1: 2$ ).

Results The median [interquartile range] tidal volume was lower with vs without nasal passage occlusion at 10 $\mathrm{cm} \mathrm{H}_{2} \mathrm{O}$ inspiratory pressure (100 [55-134] mL vs 300 [230-328] $\mathrm{mL}$, respectively; median difference $(M D), 200$ $m L$; 95\% confidence interval (CI), 157 to 229; $P<0.001$ ), $15 \mathrm{~cm} \mathrm{H}_{2} \mathrm{O}$ inspiratory pressure (190 [120-230] $\mathrm{mL}$ vs 520 [420-593] mL, respectively; $M D, 340 \mathrm{~mL} ; 95 \% \mathrm{CI}, 257$ to 395; $\mathrm{P}<0.001)$, and $20 \mathrm{~cm} \mathrm{H}_{2} \mathrm{O}$ inspiratory pressure (270
\end{abstract}

T. Yamasaki, MD · N. Komasawa, MD, PhD ( $\square)$.

H. Kido, MD, PhD - T. Minami, MD, PhD

Department of Anesthesiology, Osaka Medical College,

Daigaku-machi 2-7, Takatsuki, Osaka 569-8686, Japan

e-mail: ane078@osaka-med.ac.jp
[215-390] $m L$ vs 790 [713-823] $\mathrm{mL}$, respectively; $M D, 520$ $m L ; 95 \%$ CI, 390 to 582; $P<0.001$ ).

Conclusion Nasal passage obstruction considerably reduces tidal volume achieved during face mask ventilation. In some patients, it may be advantageous to relieve nasal airway obstruction for effective face mask ventilation.

Trial registration UMIN Clinical Trials Registry, number UMIN000022184. Registered 2 May 2016.

\section{Résumé}

Contexte Des études précédentes ont démontré que les voies nasales jouent un rôle important dans la ventilation manuelle au masque, mais aucune évaluation quantitative n'a été réalisée à ce jour. Nous avons mené une étude clinique croisée randomisée prospective afin de comparer le changement de volume courant lors de la ventilation à pression contrôlée au masque avec ou sans occlusion des voies aériennes nasales.

Méthode Des patientes subissant une chirurgie non urgente sous anesthésie générale étaient les sujets de l'étude. Les patientes ont été randomisées à une ventilation au masque débutant avec ou sans occlusion des voies nasales (réalisée à l'aide d'un pince-nez), suivie du retrait ou de l'application du pince-nez, respectivement. Après une induction standardisée de l'anesthésie générale et la paralysie musculaire, un masque bien ajusté a été appliqué sur le visage de chaque patiente, et le volume courant a été mesuré par l'appareil d'anesthésie pendant la ventilation en pression contrôlée $\left(10,15,20 \mathrm{~cm} \quad \mathrm{H}_{2} \mathrm{O} ; 8\right.$ respirations. $\min ^{-1}$; taux inspiratoire : expiratoire 1:2).

Résultats Le volume courant médian [écart interquartile] était plus bas avec vs sans occlusion des voies nasales à une pression inspiratoire de $10 \mathrm{~cm} \mathrm{H}_{2} \mathrm{O}(100$ [55-134] $\mathrm{mL}$ 
vs 300 [230-328] mL, respectivement; différence médiane (DM), $200 \mathrm{~mL}$; intervalle de confiance (IC) $95 \%, 157$ à 229; $\mathrm{P}<0,001$ ), à une pression inspiratoire de $15 \mathrm{~cm} \mathrm{H}_{2} \mathrm{O}$ (190 [120-230] mL vs 520 [420-593] mL, respectivement; DM, $340 \mathrm{~mL}$; IC $95 \%$, 257 à 395; P < 0,001), et à une pression inspiratoire de $20 \mathrm{~cm} \mathrm{H}_{2} \mathrm{O}$ (270 [215-390] $\mathrm{mL} v \mathrm{vs}$ 790 [713-823] mL, respectivement; DM, $520 \mathrm{~mL}$; IC $95 \%$, 390 à 582; $P<0,001)$.

Conclusion L'obstruction des voies nasales réduit le volume courant atteint pendant la ventilation au masque. Chez certaines patientes, il pourrait être avantageux de soulager l'obstruction des voies aériennes nasales pour une ventilation au masque efficace.

Enregistrement de l'étude Registre des études cliniques UMIN, no. UMIN000022184. Enregistrée le 2 mai 2016.

Manual face mask ventilation is an important component of airway management and typically precedes securing the airway (e.g., insertion of supraglottic device, intubation) following induction of general anesthesia. Nevertheless, some patients are at particular risk for rapid oxygen desaturation and/or difficult face mask ventilation. Not uncommonly, difficulty with face mask ventilation is encountered due to upper airway obstruction. ${ }^{1}$ Although various assist devices, such as oral airways, may improve upper airway obstruction, difficult face mask ventilation may still ensue. ${ }^{2-4}$

Recent studies have shown that the nasal passage plays an important role in manual face mask ventilation., 5 Nevertheless, quantitative assessments are lacking with respect to tidal volumes contributed via the oral and nasal passages. We hypothesized that nasal passage obstruction would decrease face mask tidal volume and evaluated this using a randomized crossover study design in elective surgical patients requiring general anesthesia.

\section{Methods}

The Osaka Medical College Research Ethics Committee approved this project (Clin-303, May 2, 2016). From JulyAugust 2016, patients requiring elective surgery in the supine position under general anesthesia were assessed for eligibility to participate in our study. Inclusion criteria included appropriately fasted females aged 20-75 yr. Exclusion criteria included patients with anticipated difficult face mask ventilation (e.g., morbid obesity, short neck, diminished thyromental distance, Mallampati score < 3 , limited mouth opening, protruding incisors, edentulous, obstructive sleep apnea) and those at risk of aspiration (e.g., non-fasted, emergency cases, pregnancy, reflux). Males were also excluded as they have been shown to be a risk factor for difficult face mask ventilation. ${ }^{1,2}$ None of the 22 patients assessed for eligibility refused to participate, and two were subsequently excluded because they did not fulfill the eligibility criteria. All subjects who participated in this study provided written informed consent.

Patients were randomly assigned (sealed envelope method) to face mask ventilation through either an oral (with nasal blockade) or an oral and nasal passage (without nasal blockade), followed by the reverse (crossover design). A nose clip used for swimming (SNC-10 ${ }^{\mathrm{TM}}$, Laxto, Japan) was applied to block airflow via the nasal passages (Figure). This device was specifically selected because it did not interfere with the face mask seal due to its small size and flat profile. Before induction of anesthesia, patients tried on the nose clip to ensure effective blockade of their nasal passages.

Patients were carefully positioned supine on the operating room table using a pillow under their head to help achieve a standardized sniffing position. To blind the operator to nose clip application, the patient's nose was covered by a non-transparent cloth that did not interfere with face mask ventilation. A medium-sized $(115 \times 95 \mathrm{~mm})$ face mask for adult females (Koo ${ }^{\text {TM }}$, Smith Medical, U.K.) was firmly applied to the patient's face, and denitrogenation was achieved by tidal volume breathing high-flow $100 \%$ oxygen for three minutes. Patients did not receive any premedication. Loss of consciousness was induced with a remifentanil infusion 0.3-0.5 $\mu \mathrm{g} \cdot \mathrm{kg}^{-1} \cdot \mathrm{min}^{-1}$ for five minutes, followed by a bolus dose of propofol $1-2 \mathrm{mg} \cdot \mathrm{kg}^{-1}{ }^{7}$ Neuromuscular blockade was achieved with rocuronium $0.9 \mathrm{mg} \cdot \mathrm{kg}^{-1}$ to minimize the risk of laryngospasm and to facilitate lung inflation. ${ }^{8}$ Following loss of consciousness, one of three

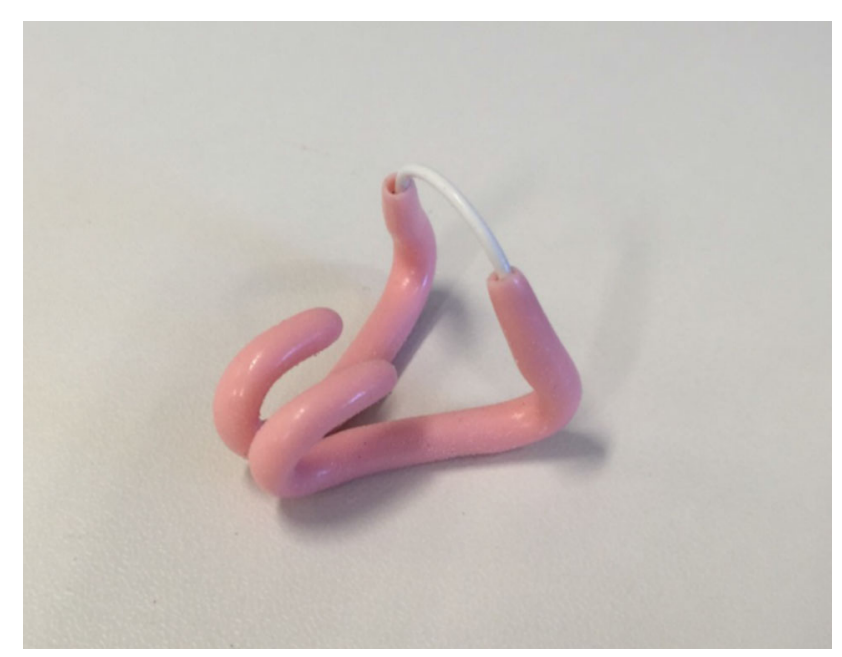

Figure Nose clip used for blocking nasal passage 
anesthesiologists with more than five years of clinical experience performed bag and face mask ventilation (3-5\% sevoflurane in an oxygen/air mixture $\left(\mathrm{F}_{\mathrm{I}} \mathrm{O}_{2}\right.$ 0.8-0.9) using the two-handed clamp technique to obtain a good face mask seal. ${ }^{9}$ As per standard clinical practice, gentle jaw thrust and chin lift were applied, as required, to achieve the best possible ventilation conditions. The patient's remained vertically oriented throughout the trial, and the use of oropharyngeal or nasopharyngeal airways was strictly avoided.

Following an initial two-minute stabilization period, during which the best possible bag and face mask ventilation conditions were established, we used the Fabius ${ }^{\circledR}$ GS anesthesia work station (Dräger, Germany; accuracy within $15 \%$ according to manufacturer) to measure the expired tidal volume during pressurecontrolled ventilation $\left(10,15,20 \quad \mathrm{~cm} \quad \mathrm{H}_{2} \mathrm{O} ; 8\right.$ breaths. $\min ^{-1}$; inspiratory:expiratory ratio of $1: 2 ; \mathrm{F}_{\mathrm{I}} \mathrm{O}_{2}$ 0.8-0.9 [air $1 \mathrm{~L} \cdot \mathrm{min}^{-1}$ and oxygen $4 \mathrm{~L} \cdot \mathrm{min}^{-1}$ ]). We began the measurements after confirming the zero count response of thumb adduction to train-of-four ulnar nerve stimulation using the TOF-Watch ${ }^{\text {TM }}$ (Nihon Kohden, Tokyo, Japan). ${ }^{10}$ Tidal volume was averaged for the eight measurements taken during a one-minute period of ventilation. Measurements were performed in a standardized ascending order of pressure-controlled volumes $(10,15$, $20 \mathrm{~cm} \mathrm{H}_{2} \mathrm{O}$ ); however, ventilation with or without nasal passage occlusion was randomly assigned for each pressure. Typically, a one-minute washout period ensued between each measurement.

\section{Statistical Analysis}

Statistical analysis was performed using JMP ${ }^{\circledR} 11$ software (SAS $^{\circledR}$ Institute Inc., Cary, NC, USA). Data are expressed as mean (standard deviation [SD]) or median [interquartile range (IQR)] where indicated. Tidal volume, the primary outcome, was compared between the groups using the Wilcoxon matched-pairs signed-rank test. A Bonferroni correction was performed for the three multiple comparisons, and Bonferroni adjusted $P$ values and confidence intervals are presented. We calculated the confidence interval by pairwise Student's $t$ distribution for mean differences. A $P$ value $<0.05$ was considered statistically significant.

In a preliminary study, six patients underwent face mask ventilation $\left(15 \mathrm{~cm} \mathrm{H}_{2} \mathrm{O}\right)$ with or without nasal passage occlusion. The mean (SD) tidal volume was 200 (100) mL and $500(200) \mathrm{mL}$ with and without nasal passage occlusion, respectively. We considered this $300 \mathrm{~mL}$ $(60 \%)$ difference to be clinically significant. Eighteen study subjects would be required to detect this difference with $80 \%$ power at a $5 \%$ significance level. In anticipation of the potential for missing data, we planned to recruit 20 patients.

\section{Results}

Characteristics of the 20 recruited patients are shown in Table 1 . None of the study subjects dropped out or were lost to follow-up. The median [IQR] tidal volume was lower with $v s$ without nasal passage occlusion at $10 \mathrm{~cm}$ $\mathrm{H}_{2} \mathrm{O}$ inspiratory pressure (100 [55-134] mL vs 300 [230$328] \mathrm{mL}$, respectively; median difference (MD), $200 \mathrm{~mL}$; 95\% confidence interval (CI), 157 to $229 ; P<0.001), 15$ $\mathrm{cm} \mathrm{H}_{2} \mathrm{O}$ inspiratory pressure $(190$ [120-230] $\mathrm{mL}$ vs 520 [420-593] mL, respectively; MD, $340 \mathrm{~mL} ; 95 \% \mathrm{CI}, 257$ to 395; $P<0.001)$, and $20 \mathrm{~cm} \mathrm{H}_{2} \mathrm{O}$ inspiratory pressure (270 [215-390] mL vs 790 [713-823] mL, respectively; MD, 520 $\mathrm{mL} ; 95 \% \mathrm{CI}, 390$ to $582 ; P<0.001$ ). (Table 2). The median $[\mathrm{IQR}]$ percentage of tidal volume reduction during nasal passage occlusion was $>60 \%$ at all inspiratory pressures $\left(10 \mathrm{~cm} \mathrm{H}_{2} \mathrm{O}, 63\right.$ [54-82]\%; $15 \mathrm{~cm} \mathrm{H}_{2} \mathrm{O}, 64$ [53-76]\%; and $20 \mathrm{~cm} \mathrm{H}_{2} \mathrm{O}, 67$ [52-72]\%).

\section{Discussion}

In this study, the volume of pressure-controlled face mask ventilation via the oral passage alone was considerably smaller compared with that achieved via the oral and nasal passages combined. Specifically, nasal passage occlusion resulted in $>60 \%$ reduction in tidal volume. Our data show the critical role of nasal airway patency during face mask ventilation.

A previous study showed the efficacy of nasal $v s$ oral passage ventilation by comparing mouth-to-mouth with mouth-to-nose ventilation in non-paralyzed patients. ${ }^{6}$ Another study showed that selective nasal ventilation (via nose mask) was more effective than combined oral and nasal ventilation in non-paralyzed patients. ${ }^{5}$ Our study extends these previous findings as we assessed the contribution of the nasal passage during conventional

Table 1 Patient characteristics in the trial

\begin{tabular}{ll}
\hline & $n=20$ \\
\hline Age $(\mathrm{yr})$ & $55(14)$ \\
Body weight $(\mathrm{kg})$ & $52(9)$ \\
Height $(\mathrm{cm})$ & $155(3)$ \\
BMI $\left(\mathrm{kg} \cdot \mathrm{m}^{-2}\right)$ & $22(4)$ \\
Mallampati score $1 / 2 / 3 / 4$ & $13 / 7 / 0 / 0$ \\
\hline
\end{tabular}

Data are shown as mean (SD) or number of patients. BMI = body mass index 
Table 2 Comparison of tidal volume with or without nose clip

\begin{tabular}{|c|c|c|c|c|c|}
\hline & $\begin{array}{l}\text { Without } \\
\text { nose clip } \\
n=20\end{array}$ & $\begin{array}{l}\text { With } \\
\text { nose } \\
\text { clip } n= \\
20\end{array}$ & $\begin{array}{l}\text { Median } \\
\text { difference }\end{array}$ & $\begin{array}{l}\text { Bonferroni- } \\
\text { adjusted } \\
95 \% \text { CIs }\end{array}$ & $\begin{array}{l}P \\
\text { value }\end{array}$ \\
\hline $\begin{array}{l}\text { Tidal volume } \\
\text { at pressure- } \\
\text { controlled } \\
\text { ventilation } \\
\text { of } 10 \mathrm{~cm} \\
\mathrm{H}_{2} \mathrm{O}(\mathrm{mL})\end{array}$ & $\begin{array}{c}300 \\
{[230-} \\
328]\end{array}$ & $\begin{array}{l}100 \\
{[55-} \\
134]\end{array}$ & 200 & 157 to 229 & $<0.001$ \\
\hline $\begin{array}{l}\text { Tidal volume } \\
\text { at pressure- } \\
\text { controlled } \\
\text { ventilation } \\
\text { of } 15 \mathrm{~cm} \\
\mathrm{H}_{2} \mathrm{O}(\mathrm{mL})\end{array}$ & $\begin{array}{l}520 \\
{[420-} \\
593]\end{array}$ & $\begin{array}{l}190 \\
{[120-} \\
230]\end{array}$ & 340 & 257 to 395 & $<0.001$ \\
\hline $\begin{array}{l}\text { Tidal volume } \\
\text { at pressure- } \\
\text { controlled } \\
\text { ventilation } \\
\text { of } 20 \mathrm{~cm} \\
\mathrm{H}_{2} \mathrm{O}(\mathrm{mL})\end{array}$ & $\begin{array}{l}790 \\
{[713-} \\
823]\end{array}$ & $\begin{array}{l}270 \\
\quad[215- \\
390]\end{array}$ & 520 & 390 to 582 & $<0.001$ \\
\hline
\end{tabular}

Data are expressed as median [interquartile range]. Data were analyzed using the Wilcoxon matched-pairs signed-rank test followed by Bonferroni correction. CIs = confidence intervals

face mask ventilation, a situation that more closely mimics routine airway management. Moreover, in our study, face mask ventilation was assessed in paralyzed patients, so the risk of potentially confounding variables, such as chest wall rigidity and laryngospasm, was reduced.

The mechanism(s) by which nasal airway patency contributes to face mask ventilation remains to be elucidated. Importantly, ventilation via the oral passage may be disrupted by glossoptosis - sinking of the root of the tongue - following induction of general anesthesia. ${ }^{11}$ The effects of glossoptosis may be lessened by nasal passage ventilation. It has been shown that nasal high-flow oxygenation decreases glossoptosis, suggesting an essential role for nasal passage ventilation to maintain oral airway patency. ${ }^{12}$

The ability to perform face mask ventilation is an essential component of anesthesia care and may be lifesaving. ${ }^{13,14}$ Typically, anesthesiologists initiate face mask ventilation during induction of general anesthesia in order to maintain appropriate oxygenation prior to securing the airway. According to the American Society of Anesthesiologists Task Force difficult airway management algorithm, ${ }^{15}$ face mask ventilation becomes critical especially when initial intubation attempts have failed. Given our findings, we consider it essential for anesthesiologists to evaluate nasal airflow (e.g., rule out nasal airway obstruction) as part of the airway examination to help predict the potential for difficult face mask ventilation. We speculate that this may be particularly important for patients with obstructive sleep apnea syndrome, as they are at an elevated risk for difficult face mask ventilation following induction of anesthesia. ${ }^{16,17} \mathrm{We}$ would also emphasize the potential advantage of using nasal airway "trumpets" to alleviate nasal passage obstruction when face mask ventilation is difficult. ${ }^{18,19}$ Furthermore, administration of a nasal decongestant may be advantageous to improve nasal passage patency before (or during) face mask ventilation.

There are several limitations to our study. Most importantly, as our subjects were females at low risk of difficult face mask ventilation, caution must be exercised when attempting to apply these observations to those at higher risk (e.g., see exclusion criteria above). Furthermore, we acknowledge that excluding males as study subjects may bias our findings considerably. Although we attempted to blind the operator by covering the patient's face, the nose clip may have been evident. Moreover, it is impossible to rule out confounding variables (e.g., differences in face mask ventilation technique) from operator to operator, and it is hard to maintain a rigorously standardized head position from patient to patient. In addition, differences in the depth of anesthesia, muscle relaxation, and lung and chest wall compliance are potential confounding variables that can influence the efficiency of face mask ventilation. Nevertheless, we emphasize that each study subject served as her own control; therefore, the potential impact of some of these confounding variables is arguably lessened.

In summary, nasal passage obstruction considerably reduces tidal volume achieved during face mask ventilation. In some patients, it may be advantageous to relieve nasal airway obstruction for effective face mask ventilation. In order to validate the generalizability of our findings, future studies are required to evaluate the contribution of the nasal passage in patients with risk factors for difficult face mask ventilation (including males).

Conflict of interest None declared.

Declaration of interest The authors have no affiliation with the manufacturers of the devices described in this manuscript and declare no financial interest in the material described herein.

Editorial responsibility This submission was handled by Dr. Steven Backman, Associate Editor, Canadian Journal of Anesthesia.

Author contributions Tomoki Yamasaki and Nobuyasu Komasawa contributed to the study design and statistical analysis. Haruki Kido contributed to data collection and offered criticism of both manuscript preparation and data interpretation. Tomoki Yamasaki, Nobuyasu Komasawa, and Toshiaki Minami contributed to study implementation and manuscript preparation. All authors discussed the methods and results. 
Funding Financial support for the study was provided by the authors' affiliated institutions.

\section{References}

1. Langeron $O$, Masso E, Huraux $C$, et al. Prediction of difficult mask ventilation. Anesthesiology 2000; 92: 1229-36.

2. Yildiz TS, Solak M, Toker $K$. The incidence and risk factors of difficult mask ventilation. J Anesth 2005; 19: 7-11.

3. Combes $X$, Le Roux B, Suen $P$, et al. Unanticipated difficult airway in anesthetized patients: prospective validation of a management algorithm. Anesthesiology 2004; 100: 1146-50.

4. Kheterpal $S$, Han $R$, Tremper $K K$, et al. Incidence and predictors of difficult and impossible mask ventilation. Anesthesiology 2006; 105: 885-91.

5. Jiang Y, Bao FP, Liang $Y$, et al. Effectiveness of breathing through nasal and oral routes in unconscious apneic adult human subjects: a prospective randomized crossover trial. Anesthesiology 2011; 115: 129-35.

6. Liang Y, Kimball WR, Kacmarek RM, Zapol WM, Jiang Y. Nasal ventilation is more effective than combined oral-nasal ventilation during induction of general anesthesia in adult subjects. Anesthesiology 2008; 108: 998-1003.

7. Komasawa N, Kido H, Miyazaki Y, Tatsumi S, Minami T. Cricoid pressure impedes tracheal intubation with the Pentax-AWS Airwayscope $^{\circledR}$ : a prospective randomized trial. $\mathrm{Br} \mathrm{J}$ Anaesth 2016; 116: 413-6.

8. Komasawa N, Nishihara I, Minami T. Relationship between timing of sugammadex administration and development of laryngospasm during recovery from anaesthesia when using supraglottic devices: a randomised clinical study. Eur J Anaesthesiol 2016; 33: 691-2.
9. Joffe AM, Hetzel S, Liew EC. A two-handed jaw-thrust technique is superior to the one-handed "EC-clamp" technique for mask ventilation in the apneic unconscious person. Anesthesiology 2010; 113: 873-9.

10. Hattori K, Komasawa N, Miyazaki Y, Kido H, Deguchi S, Minami $T$. Muscle relaxant facilitates i-gel insertion by novice doctors: a prospective randomized controlled trial. J Clin Anesth 2016; 33: 218-22.

11. Greenberg RS. Facemask, nasal, and oral airway devices. Anesthesiol Clin North America 2002; 20: 833-61.

12. Itagaki T, Okuda $N$, Tsunano $Y$, et al. Effect of high-flow nasal cannula on thoraco-abdominal synchrony in adult critically ill patients. Respir Care 2014; 59: 70-4.

13. Chong SE, Mohammad Zaini RH, Wan Mohd Rubi I, Lim JA. Difficult mask ventilation: simple step to make the impossible, possible! J Clin Anesth 2016; 34: 612-4.

14. Peterson GN, Domino KB, Caplan RA, Posner KL, Lee LA, Cheney $F W$. Management of the difficult airway: a closed claims analysis. Anesthesiology 2005; 103: 33-9.

15. Apfelbaum JL, Hagberg CA, Caplan RA, et al. Practice guidelines for management of the difficult airway: an updated report by the American Society of Anesthesiologists Task Force on Management of the Difficult Airway. Anesthesiology 2013; 118: 251-70.

16. Isono $S$. Obesity and obstructive sleep apnoea: mechanisms for increased collapsibility of the passive pharyngeal airway. Respirology 2012; 17: 32-42.

17. Tsuiki S, Isono S, Ishikawa T, Yamashiro Y, Tatsumi K, Nishino T. Anatomical balance of the upper airway and obstructive sleep apnea. Anesthesiology 2008; 108: 1009-15.

18. Metz S. Perioperative use of the modified nasal trumpet in 346 patients. Br J Anaesth 2004; 92: 694-6.

19. Metz $S$, Beattie $C$. A modified nasal trumpet to facilitate fibreoptic intubation. Br J Anaesth 2003; 90: 388-91. 